\title{
The anti-inflammatory Annexin A1 induces the clearance and degradation of the amyloid- $\beta$ peptide
}

Miriam Ries ${ }^{1}$, Rodrigo Loiola ${ }^{2}$, Urvi N. Shah', Steve M. Gentleman ${ }^{1}$, Egle Solito ${ }^{2^{*}+}$ and Magdalena Sastre ${ }^{1 *+}$

\begin{abstract}
Background: The toxicity of amyloid- $\beta$ (A $\beta$ ) peptide present in the brain of Alzheimer's disease (AD) patients is thought to be mediated via the increased secretion of pro-inflammatory mediators, which can lead to neuronal dysfunction and cell death. In addition, we have previously shown that inflammation can affect A $\beta$ generation. More recently, we have reported that in vitro administration of the anti-inflammatory mediator Annexin A1 (ANXA1) following an inflammatory challenge suppressed microglial activation and this effect was mediated through formyl peptide receptor-like 1 (FPRL1/FPR2) signalling. The aim of this study was to determine the potential role of ANXA1 in the generation and clearance of $A \beta$.

Methods: We first compared ANXA1 protein expression in the brains of AD patients and healthy controls as well as in the 5XFAD model of AD. To determine the role of ANXA1 in the processing of amyloid precursor protein (APP) and the degradation of $A \beta, N 2 a$ neuroblastoma cells were treated with human recombinant ANXA1 or transfected with ANXA1 siRNA. We also investigated the effect of ANXA1 on A $\beta$ phagocytosis and microglial activation in BV2 cells treated with synthetic $A \beta$.
\end{abstract}

Results: Our data show that ANXA1 is increased in the brains of AD patients and animal models of AD at early stages. ANXA1 was able to reduce the levels of A 3 by increasing its enzymatic degradation by neprilysin in N2a cells and to stimulate $A \beta$ phagocytosis by microglia. These effects were mediated through FPRL1 receptors. In addition, ANXA1 inhibited the A $\beta$-stimulated secretion of inflammatory mediators by microglia.

Conclusions: These data suggest that ANXA1 plays a pivotal role in A $\beta$ clearance and supports the use of ANXA1 as potential pharmacological tool for AD therapeutics.

Keywords: Inflammation, Annexin A1, Alzheimer's disease, Microglia, Amyloid- $\beta$, Anti-inflammatory, Neprilysin, Formyl-peptide receptor

Abbreviations: $A B C$, Avidin biotin complex; AD, Alzheimer's disease; AICD, Amyloid precursor protein intracellular domain; ANOVA, Analysis of variance; ANXA1, Annexin A1; APP, Amyloid precursor protein; A $\beta$, Amyloid beta; BACE1, Beta-site APP cleaving enzyme 1; BBB, Blood-brain barrier; BSA, Bovine serum albumin; CALLA, Common acute lymphocytic leukaemia (ALL) antigen; CTF, Carboxy-terminal fragment; ELISA, Enzymelinked immunosorbent assay; FACS, Fluorescence-activated cell sorting; FAD, Familial Alzheimer's disease; FBS, Foetal bovine serum; FPR, Formyl peptide receptor; FPRL1, Formyl peptide receptor-like 1; hrANXA1, Human (Continued on next page)

\footnotetext{
* Correspondence: e.solito@qmul.ac.uk; m.sastre@imperial.ac.uk

${ }^{\dagger}$ Equal contributors

${ }^{2}$ William Harvey Research Institute, Barts and The London School of Medicine

and Dentistry, Queen Mary University of London, Charterhouse Square,

London EC1M 6BQ, UK

'Division of Brain Sciences, Hammersmith Hospital, Imperial College London,

London W12 ONN, UK
} 


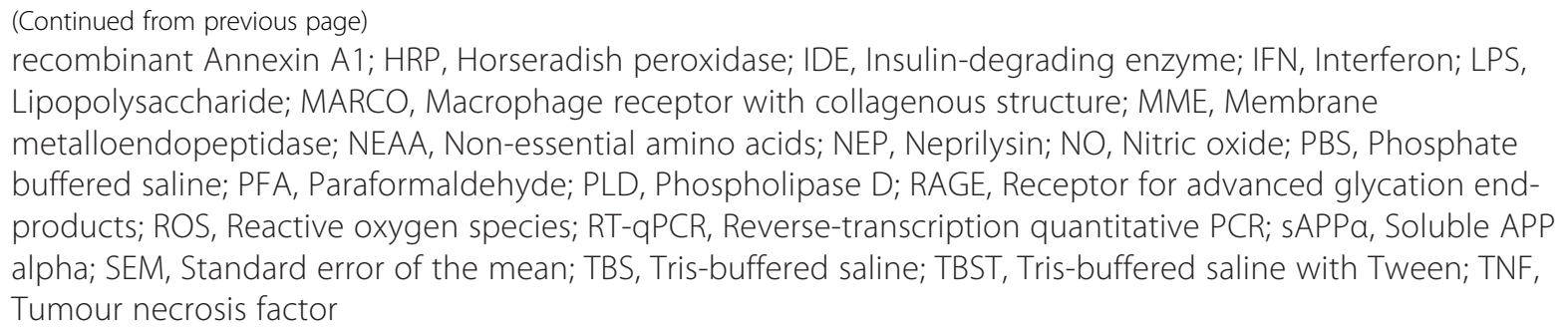

\section{Background}

Amyloid- $\beta$ (A $\beta$ ) peptide is present in high levels in the brains of Alzheimer's disease (AD) patients and is closely associated with the pathogenesis of the disease. $A \beta$ peptides are toxic products derived from the catalytic cleavage of a larger amyloid precursor protein (APP) by $\beta$ - and $\gamma$ secretases [1]. The toxicity of $A \beta$ is thought to be mediated via the secretion of neurotoxic inflammatory mediators and reactive oxygen species (ROS) from glial cells [2]. There is convincing evidence that $A \beta$ is able to prime microglia [3], inciting an inflammatory response and the release of neurotoxic cytokines, ROS, complement factors and nitric oxide (NO), which can all contribute to neuronal dysfunction and cell death [4]. Importantly, we previously found a direct link between pro-inflammatory cytokines and $A \beta$ generation by showing that certain cytokines such as tumour necrosis factor (TNF) $\alpha$ and interferon $($ IFN) $\gamma$ can transcriptionally upregulate $\beta$-secretase beta-site APP cleaving enzyme 1 (BACE1) $[5,6]$; this has also been confirmed in animal models of inflammation [7]. Therefore, a combination of dying neurones and $A \beta$ accumulated via active synthesis would further stimulate microglia, creating a self-perpetuating cycle. It has to be noted that the activation of microglia may not only contribute to disease progression but could also have beneficial effects. Activated microglia can reduce $\mathrm{A} \beta$ accumulation by increasing its phagocytosis, clearance and degradation $[8,9]$ and the release of anti-inflammatory molecules including certain cytokines, growth factors and the resolving molecule Annexin A1 (ANXA1).

ANXA1 is a glucocorticoid anti-inflammatory mediator in the peripheral system $[10,11]$, which plays a key role in ensuring the effective and selective removal of apoptotic neuron-like cells under inflammatory and non-inflammatory conditions [12]. In the brain, ANXA1 is abundant in microglial cells and in the endothelium of the blood brain barrier (BBB), where it plays an important role in maintaining BBB tightness [13, 14]. Microglia have the capacity to synthesise and release ANXA1 [15], and ANXA1 function is associated with anti-inflammatory actions, regulating leukocyte extravasation [16-18], macrophage phagocytosis [19] and glucocorticoid action [20-22]. During pathological states, it has been proposed that ANXA1 has a protective role by limiting inflammatory damage [23]. This was further supported by our observations whereby incubation of microglia with recombinant ANXA1 resulted in reduced microglial activation following lipopolysaccharide (LPS) stimulation [12]. Our studies have also shown that ANXA1 is upregulated in human microglia surrounding $A \beta$ plaques, supporting a possible role for the protein in regulating the microglial response to amyloid plaques [12, 15]. The identification of formyl peptide receptor-like 1 (FPRL1/FPR2) as a receptor for ANXA1 suggests an intriguing link between $A \beta$ and FPRL1 [24]. The binding of ANXA1 to FPRL1 has been associated with the modulation of microglial phagocytosis [12, 25] and pro-inflammatory release [26], while it was suggested that the interaction of different aggregated/fibrillar forms of $A \beta$ with microglia changes the expression pattern of FPRL1, affecting the phagocytic function of microglia [27].

We therefore hypothesized that ANXA1 has a protective role in resolving neuroinflammation in the $A D$ brain, by affecting $A \beta$ generation and/or degradation and modulating microglial functions such as phagocytosis and the secretion of cytokines and neurotoxic species, which could cause neuronal damage. The aim of this study was to define the role of ANXA1 in APP processing and $A \beta$ degradation in vitro and to evaluate whether ANXA1 is able to affect $A \beta$-induced changes in microglia function.

\section{Methods \\ Reagents and antibodies}

Antibodies used included 6E10 against A $\beta 1-16$ (Covance), 4G8 against A $\beta 17-24$ (Covance), anti-BACE1 antibody (Cell Signalling), anti-neprilysin antibody (Santa Cruz), anti-insulin degrading enzyme (IDE) antibody (Abcam), anti-ANXA1 antibody (Zymed), anti- $\beta$-actin antibody (Abcam), anti-IgG antibody (Abcam), anti-FPRL1/FPR2 antibody (Acris Antibodies $\mathrm{GmbH}$ ) and anti-IgG FITC conjugated antibody (AbD Serotec). Full-length human recombinant (hr) ANXA1 was obtained as previously described [16], and protein was purified by GTP Technology (Labege Cedex). Synthetic $A \beta_{1-42}$, 5-FAM-labelled $A \beta_{1-42}$ and $A \beta_{1-42}$ scrambled peptides were obtained from Anaspec. Synthetic $A \beta_{1-42}$ was prepared by suspension of the lyophilised $A \beta_{1-42}$ in DMSO to $500 \mu \mathrm{M}$ and then diluted to different concentrations ranging from 0.1 to $3 \mu \mathrm{M}$ with 
cold DMEM. FPR2 inhibitors WRW4 and Boc-1 were obtained from Tocris Bioscience. Tissue culture reagents were obtained from Invitrogen. All other chemicals and reagents were purchased from Sigma-Aldrich, Qiagen and Invitrogen.

\section{Human postmortem brain samples}

Human brains were obtained from routine autopsies at the London Neurodegenerative Diseases Brain Bank at King's College London and the Swedish Brain Bank in accordance with laws and the permission of the ethical committees. The control group included brains from subjects who died either of non-neurological diseases or traffic accidents and had no history of long-term illness or dementia. Frontal cortex was compared of control brains $(n=20,12$ males, 8 females, range 40-97 years, mean age $73.24 \pm 4$ years $)$ and sporadic $\mathrm{AD}$ cases $(n=22$, 11 males, 11 females, range $42-98$ years, mean age $79.09 \pm 3$ years).

\section{Immunohistochemistry}

For immunohistochemistry, sections were deparaffinised in xylene and rehydrated in decreasing alcohols. Endogenous peroxidase was inhibited by incubation in $0.3 \% v / v \mathrm{H}_{2} \mathrm{O}_{2}$ in $0.1 \mathrm{M}$ phosphate buffered saline (PBS) for $30 \mathrm{~min}$ at room temperature. Sections were rinsed twice in $0.05 \mathrm{M}$ Tris-buffered saline (TBS) and incubated for $1 \mathrm{~h}$ at room temperature with $10 \%$ BSA (Sigma-Aldrich) containing $0.05 \% v / v$ Triton X-100 to saturate nonspecific binding; sections were then incubated for $16 \mathrm{~h}$ at $4{ }^{\circ} \mathrm{C}$ with ANXA1 antibody (1:1000), rinsed twice in TBS-containing $0.05 \% v / v$ Triton X-100, incubated in biotinylated goat-anti-rabbit secondary antibody (Vector Laboratories) at the dilution of 1:100 for $2 \mathrm{~h}$ at room temperature, rinsed twice with TBS and incubated for $45 \mathrm{~min}$ in the avidin-biotin complex $(\mathrm{ABC})$ conjugated with horseradish peroxidase (HRP) in TBS (Vector Laboratories). Following two washes in TBS, the reactions were developed in $0.025 \%$ diaminobenzidine and $0.01 \% \mathrm{H}_{2} \mathrm{O}_{2}$ (Sigma-Aldrich) in TBS for $5 \mathrm{~min}$. Sections were rinsed twice in TBS, dehydrated and mounted under DPX mountant (VWR International) for bright-field microscopic analysis.

\section{Animals}

All animals were kept in individually ventilated cages with controlled temperature and humidity, food and water ad libitum and a 12:12-h light-dark cycle. Twelveand 26-month-old male 5XFAD transgenic mice and their wild-type littermates ( $n=6$ per group) were used and were obtained from the Jackson Laboratory. These mice overexpress both mutant human $\operatorname{APP}(695)$ with the Swedish (K670N, M671L), Florida (I716V) and London (V717I) Familial Alzheimer's Disease (FAD) mutations and human PS1 harbouring two FAD mutations, M146L and L286V. Expression of both transgenes is regulated by neural-specific elements of the mouse Thy 1 promoter to drive overexpression in the brain. 5XFAD mice generate almost exclusively $A \beta_{42}$ and rapidly accumulate massive cerebral levels [28]. Animals were anaesthetised and transcardially perfused with icecold $0.9 \%$ saline. Brains were dissected and snap frozen and were stored at $-80{ }^{\circ} \mathrm{C}$ until used. All animal procedures were approved by the UK Home Office and were in accordance with the Animals (Scientific Procedures) Act of 1986.

\section{Cell lines and maintenance}

The murine neuroblastoma cell line stably transfected with the APP "Swedish" mutation (K595N/M596L), hereafter referred to as N2asw, was a kind gift of G. Thinakaran (University of Chicago). Cells were maintained in a selective and undifferentiated state using $0.2 \mathrm{mg} / \mathrm{ml}$ of the antibiotic G-418 in DMEM and Opti-MEM (Gibco/Life Technologies), supplemented with $5 \%$ foetal bovine serum (FBS) and $50 \mathrm{U} / \mathrm{ml}$ penicillin, and $50 \mathrm{mg} /$ $\mathrm{ml}$ streptomycin sulphate. The human neuroblastoma cell line SK-N-SH was cultured in DMEM supplemented with $10 \%$ FBS, $100 \mathrm{U} / \mathrm{ml}$ penicillin and $100 \mathrm{mg} / \mathrm{ml}$ streptomycin sulphate. The murine microglial cell line BV2 was cultured in Roswell Park Memorial Institute (RPMI) medium containing $5 \%$ FBS, gentamycin (50 $\mathrm{mg} / \mathrm{ml}$ ) and $1 \%$ non-essential amino acids (NEAA). Cells were grown in a $5 \% \mathrm{CO}_{2}$ incubator at $37^{\circ} \mathrm{C}$.

\section{Treatments, transfection and infection}

Cells were incubated with different concentrations of human recombinant ANXA1 (hrANXA1), ranging from 0.04 to $5 \mu \mathrm{g} / \mathrm{ml}$ for $2-48 \mathrm{~h}$ in serum-free medium. In some experiments, hrANXA1 treatment was combined with $0.1-3 \mu \mathrm{M}$ synthetic $A \beta_{42}$ (Anaspec), non-selective FPR inhibitor Boc1 $(5 \mu \mathrm{g} / \mathrm{ml})$ or FPR2 inhibitor WRW4 $(0.5-5 \mu \mathrm{M})$, with hrANXA1 added 30 min before $A \beta$ and Boc1 or WRW4 added $20 \mathrm{~min}$ before hrANXA1. For fluorescence-activated cell sorting (FACS) experiments, BV2 cells were left in medium (containing FBS) which they had conditioned overnight for $18 \mathrm{~h}$, or this was changed to fresh medium (containing FBS), prior to addition of 5-FAM-labelled-A $\beta_{42}$ or $\mathrm{A} \beta_{42}$ scrambled $(3 \mu \mathrm{g} / \mathrm{ml})$ and anti-ANXA1-antibody $(20 \mathrm{ng} / \mathrm{ml})$ or antiIgG-antibody $(20 \mathrm{ng} / \mathrm{ml})$ for $3 \mathrm{~h}$. For Image Stream experiments, cells were incubated with 5-FAM-labelled$\mathrm{A} \beta_{42}$ or $\mathrm{A} \beta_{42}$ scrambled $(5 \mu \mathrm{g} / \mathrm{ml})$, with $5 \mu \mathrm{g} / \mathrm{ml}$ hrANXA1 added 30 min before $A \beta$ and $5 \mu \mathrm{M}$ WRW4 added 20 min before hrANXA1.

N2asw cells were transfected with control or ANXA1 small interfering RNA (siRNA) (Gene Pharma) using Lipofectamine 2000 transfection reagent (Thermo Fischer 
Scientific) according to the manufacturer's instructions and harvested after $48 \mathrm{~h}$.

BV2 cells were plated in six-well plates $(300,000$ cells/ well). After $48 \mathrm{~h}$, when having reached $70-80 \%$ of confluence, cells were incubated for $18 \mathrm{~h}$ overnight at $37{ }^{\circ} \mathrm{C}$ with medium containing lentivirus small hairpin RNA (shRNA) murine ANXA1 with designated specific clones named TRCN0000109725(A) and TRCN0000109728 (B) as previously described [29]. Mock-infected cells (PKCO) were used as control of infection procedure. Transduction efficiency and ANXA1 knockdown were verified by Western blot analysis (Additional file 1: Figure S1).

\section{Analysis of $A \beta$ and sAPPa}

Soluble APP $\alpha$ (sAPP $\alpha)$ and A $\beta$ secreted in the conditioned medium of N2asw cells were analysed by Western blot. The volume of medium used was adjusted to protein concentrations measured in total cell lysates. An aliquot of the media was either run straight away on NuPage 4-12 \% Tris-glycine gel (Invitrogen) or $A \beta$ was pulled down overnight at $4{ }^{\circ} \mathrm{C}$ using Sepharose Protein A (Zymed) and 4G8 (Covance). Samples were then loaded in NuPage 4-12 \% Tris-glycine gels and transferred onto nitrocellulose membranes. The membrane was boiled in PBS for 5 min, blocked with non-fat milk and incubated with 6E10 antibody at 1/1000 (a monoclonal antibody recognising amino acids 1-17 of human A $\beta$ (Covance)). Membranes were incubated with HRP conjugated secondary in $5 \%$ non-fat dried milk in Trisbuffered saline with Tween (TBST) and developed using ECL $^{\mathrm{mm}}$ (GE Amersham) and Hyperfilm ECL ${ }^{\mathrm{mx}}$ (GE Amersham) in an automated developer from Konica, SRX 101A.

\section{Western blotting analysis}

Cell lysates and brain homogenates were extracted with RIPA (1 \% Triton X-100, 1 \% sodium deoxycholate, $0.1 \%$ SDS, $150 \mathrm{mM} \mathrm{NaCl}$, and $50 \mathrm{mM}$ Tris- $\mathrm{HCl}, \mathrm{pH}$ 7.2) supplemented with cOmplete ${ }^{\mathrm{m}}$ protease inhibitor cocktail (Roche), and equal amounts of protein samples $(20-80 \mu \mathrm{g})$ were separated in SDS-PAGE gels, followed by immunoblotting with primary antibodies and detected with HRP conjugated secondary in $5 \%$ non-fat dried milk or $5 \%$ bovine serum albumin (BSA) in TBST. Membranes were developed using ECL ${ }^{\mathrm{nt}}$ (GE Amersham) reagents and using Hyperfilm ECL ${ }^{\mathrm{ma}}$ in an automated developer from Konica, SRX 101A. To re-probe blots for a different protein, membranes were stripped with ReBlot Plus Strong Antibody Stripping Solution (Millipore). Digital images were quantified by densitometry using Image and adjusted for protein loading by normalising to $\beta$-actin, GAPDH or tubulin, or full-length APP for APP cleavage products.

\section{$\beta$-secretase activity assay}

$\beta$-secretase enzyme activity was measured in N2asw cell lysates using a fluorimetric reaction (Abcam) according to the manufacturer's instructions.

\section{Neprilysin activity assay}

Treated cells were collected and resuspended in $10 \mathrm{mM}$ Tris- $\mathrm{HCl} \mathrm{pH} 7.5$ and incubated with $100 \mathrm{mM}$ substrate $\mathrm{N}$-succinyl alanin-alanin-phenylalanin-7-amino-4-methylcoumarin (Sigma) for $30 \mathrm{~min}$ at $37^{\circ} \mathrm{C}$. Fluorescence was measured at 390-nm excitation and 420-nm emission wavelength, and results were adjusted to protein concentration [30].

\section{qPCR}

Messenger RNA (mRNA) was extracted from treated cells using the Direct-zol RNA Mini Prep system (Zymo Research) according to the manufacturer's instructions. mRNAs were subjected to reverse-transcription quantitative PCR (RT-qPCR) analysis using a two-step method with an initial RT and subsequent real-time cycling as reported previously [30] on a Stratagene Mx3000p block cycler. GAPDH/Gapdh was used as an internal control for mRNA. Primers used are listed in Table 1.

\section{Fluorescence-activated cell sorting}

BV2 microglial cells were plated in a 12-well plate overnight in RPMI containing 5 \% FBS. The following day, the medium was either replaced with RPMI containing $1 \%$ FBS or unchanged, and the cells were then incubated with $3 \mu \mathrm{g} / \mathrm{ml}$ of 5 -FAM-labelled $A \beta_{1-42}$ or 5FAM-labelled scrambled-A $\beta_{1-42}$, for $3 \mathrm{~h}$. Following this, the medium was removed and the cells were washed with cold PBS and fixed with $2 \%$ paraformaldehyde (PFA) for $10 \mathrm{~min}$. After this, cells were washed and collected for analysis by FACS using FACSCalibur (Becton,

\begin{tabular}{|c|c|c|}
\hline Gene & Forward & Reverse \\
\hline$\overline{\operatorname{Arg} 1}$ & CAGCACTGAGGAAAGCTGGT & CAGACCGTGGGTTCTTCACA \\
\hline BACE1 & GGCGGGAGTGGTATTATGAGGTGA & TATTGCTGCGGAAGGATGGTGA \\
\hline FPR rsl & CCTTGGACCGCTGTATTTGT & GTGCACATCCCCTCTAGCAT \\
\hline Gapdh & ACCACAGTCCATGCCATCAC & TCCACCACCCTGTTGCTGTA \\
\hline GAPDH & AGGGCTGCTITTAACTCTGGT & CCCCACTTGATTITGGAGGGA \\
\hline 1110 & TAACTGCACCCACTTCCCAG & AGGCTTGGCAACCCAAGTAA \\
\hline 114 & GGTCTCAACCCCCAGCTAGT & GCCGATGATCTCTCTCAAGTGAT \\
\hline 116 & ATGGATGCTACCAAACTGGAT & TGAAGGACTCTGGCTITGTCT \\
\hline MARCO & ACAGAGCCGATTTTGACCAAG & CAGCAGTGCAGTACCTGCC \\
\hline MME & GGTCCGCAGCTAAGGTCCAG & GAGCTGGTCTCGGGAATGAC \\
\hline RAGE & СTTGCTCTATGGGGAGCTGTA & GGAGGATTTGAGCCACGCT \\
\hline Tgfb 1 & GGATACCAACTATTGCTTCAGCTCC & AGGCTCCAAATATAGGGGCAGGGTC \\
\hline Tnf & AGGGATGAGAAGTTCCCAAATG & CACTTGGTGGTTTGCTACGAC \\
\hline
\end{tabular}


Dickinson and Company) with a 100-mW, 488-nm, aircooled argon laser. Data was measured from the FL1 channel (mean intensity of fluorescence in log scale) with at least 10,000 events counted and analysed using FlowJo software.

\section{Image stream}

BV2 cells (wild type, shRNA PKCO and shRNA ANXA1 492) were plated in sixwell plates. After $24 \mathrm{~h}$, cells were incubated for $3 \mathrm{~h}$ at $37{ }^{\circ} \mathrm{C}$ with $5 \mu \mathrm{g} / \mathrm{ml}$ of 5-FAM-labelled $A \beta_{1-42}$ added to $B V 2$-conditioned medium. In order to investigate the effect of ANXA1 on $A \beta_{1-42}$ phagocytosis, cells were pre-incubated with hrANXA1 $(5 \mu \mathrm{g} / \mathrm{ml}) 30 \mathrm{~min}$ prior incubation with 5-FAM-labelled $A \beta_{1-42}$. To further evaluate the involvement of FPR2 on $A \beta_{1-42}$ phagocytosis, cells were pre-incubated with WRW4 $(5 \mu \mathrm{M}) 20$ min prior to incubation with hrANXA1. Following phagocytosis, cells were washed three times with cold PBS and detached from plates by using trypsin $(0.20 \%)$. Cells collected were fixed with $2 \%$ PFA for $10 \mathrm{~min}$ at room temperature. Imaging flow cytometry was performed on an ImageStreamx Mark II operated by INSPIRE software (Amnis Corporation). The 5-FAM-labelled $A \beta_{1-42}$ fluorescence was recorded using excitation with a $488-\mathrm{nm}$ laser at $50-\mathrm{mW}$ intensity and emission collected with a 480-560-nm filter in the camera $2(\mathrm{CH} 2)$, while bright-field images were collected in the cameras $1(\mathrm{CH} 1)$ and $9(\mathrm{CH} 9)$. A sample of BV2 cells that were not incubated with 5-FAM-labelled $\mathrm{A} \beta_{1-42}$ (control-negative phagocytosis) was collected at the same settings, in order to gate different cell populations (negative or positive phagocytosis). Image-based gating was performed following the method reported in detail in Additional file 2 and Additional file 3: Figure S3. In each experiment, a template of settings used to analyse control cells was created and was applied to all files. A total of 10,000 events were collected for each sample, and data were analysed using IDEAS Application 6.1 software (Amnis Corporation).

\section{Statistical analysis}

Data shown are mean \pm standard error of the mean (SEM). Statistical analysis was performed using GraphPad Prism 5 software. One- or two-way analysis of variance (ANOVA) with Bonferroni's multiple-comparison post hoc test were used, or when appropriate, a Kruskal-Wallis test with Dunn's multiple-comparison post-test or an independent two-tailed Student's $t$ test, with a value of $p<0.05$ being considered statistically significant.

\section{Results}

ANXA1 is increased in postmortem brains of AD patients and in 5XFAD mice

ANXA1 expression was determined in homogenates of human postmortem frontal cortex from AD patients and in age-matched healthy control brains. The results obtained from Western blotting analysis revealed an increase of $\sim 20 \%$ in the expression of ANXA1 (37 kDa) in $\mathrm{AD}$ brains compared with matched controls $(n=21$ controls and 22 sporadic AD cases, Fig. 1a). Supporting data obtained in human AD cases, a $50 \%$ increase in ANXA1 expression was also observed in brain homogenates of 5XFAD mice at 12 weeks of age $(n=6 /$ group, Fig. 1b). However, at 26 weeks of age, when the animals show extensive amyloid plaque deposition, there were no significant differences in ANXA1 levels between 5XFAD mice and wild-type controls. We did not observe changes in FPRL1/FPR2 expression in either AD patients (Additional file 4: Figure S4A) or animal models (Additional file 4: Figure S4B).

In addition, immunostaining of ANXA1 in hippocampal sections from AD patients showed neuronal (Fig. 1c) as well as microglial (Fig. 1d) and astrocytic (Fig. 1e) staining. Intriguingly, ANXA1 was highly expressed in neuronal tangles (marked by arrows), indicating a potential role of ANXA1 in neuronal pathology in AD.

\section{Treatment of neuroblastoma cells with recombinant ANXA1 reduces the levels of soluble $A \beta$}

Because ANXA1 is expressed by neurons (Fig. 1c), we investigated the effect of ANXA1 on APP processing in a neuroblastoma cell line. Consequently, N2asw cells were incubated for $18 \mathrm{~h}$ with different concentrations of hrANXA1 ranging from 0.5 to $4 \mu \mathrm{g} / \mathrm{ml}$ (corresponding to 13 to $105 \mathrm{nM}$ ). Our data show that hrANXA1 induced a concentration-dependent decrease in the levels of $A B$ in the media of these cells (Fig. 2a). Conversely, ANXA1 knockdown using siRNA transfection resulted in an increase in $A \beta$ secretion (Fig. 2a).

The reduction in $A \beta$ was not secondary to alterations in the expression of APP or the processing of APP by $\alpha$ secretase, as no changes were detected in the expression of full-length APP in cell lysates (Fig. 2b) or in sAPP $\alpha$ in the conditioned medium (Fig. 2c). To determine whether incubation with recombinant ANXA1 decreased $A \beta$ by altering the amyloidogenic pathway, the levels of $\beta$-carboxy-terminal-fragments (CTFs), as measurement of $\beta$-secretase activity, were quantified, showing no changes with hrANXA1 treatment (Fig. 3a). Similar results were obtained performing an in vitro $\beta$-secretase assay (Fig. 3e). Additionally, no effects on the BACE1 protein and BACE1 mRNA expression by treatment with hrANXA1 $(0.5-2 \mu \mathrm{g} / \mathrm{ml})$ were confirmed in N2asw and in human neuroblastoma SK$\mathrm{N}-\mathrm{SH}$ cells (Fig. 3b-d).

Therefore, these results suggest that ANXA1 reduces $A \beta$ levels in neurons, and this effect is not mediated by changes in the expression or enzymatic cleavage of APP. 
A
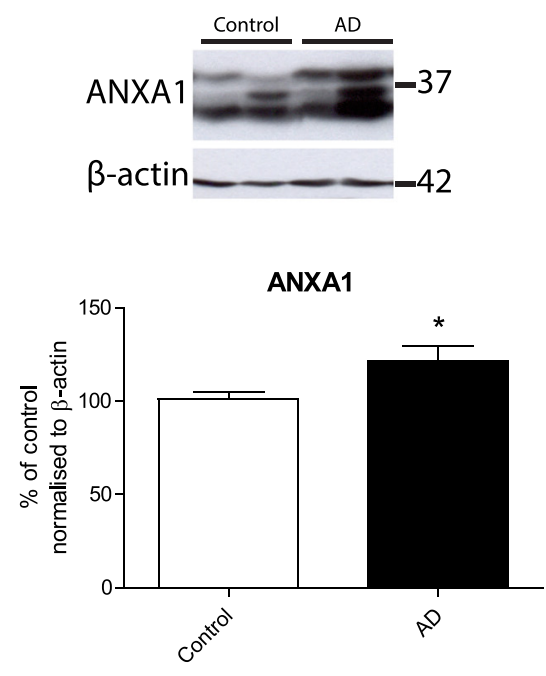

C

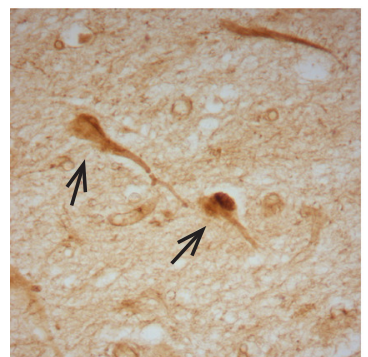

D

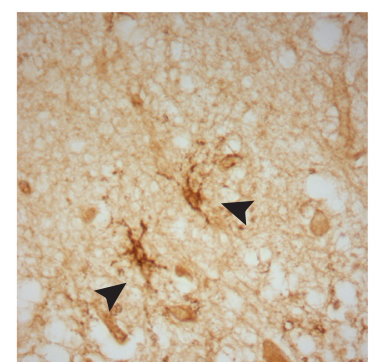

B
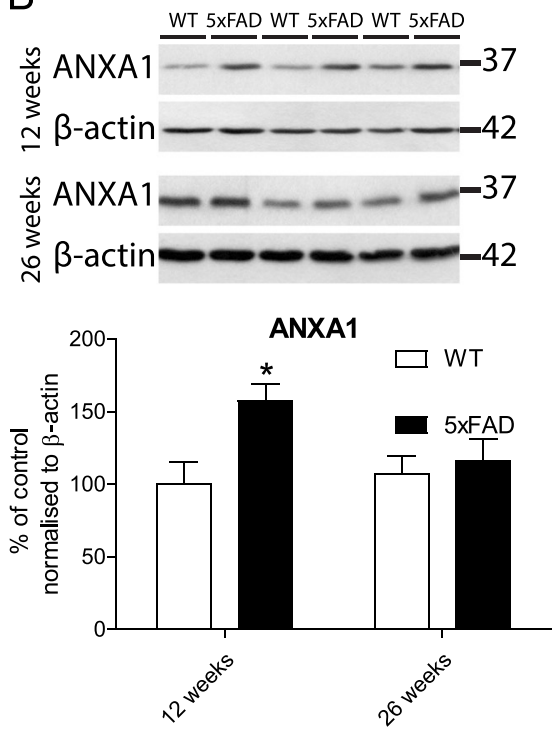

$\mathrm{E}$

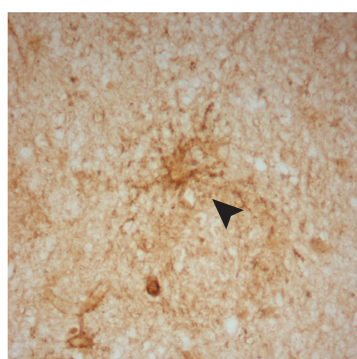

Fig. 1 ANXA1 is increased in postmortem brains of AD patients and in 5XFAD mice. a Representative blots and quantification of ANXA1 expression in the frontal cortex of neurologically healthy controls and sporadic Alzheimer's patients and normalised to $\beta$-actin ( $n=20$ controls, 12 males, 8 females, range 40-97 years, mean age $73.24 \pm 4$ years, $n=22$ AD cases, 11 males, 11 females, range $42-98$ years, mean age $79.09 \pm 3$ years). b Representative blots and quantification of ANXA1 expression in the cortex of 5XFAD mice and wild-type littermates and normalised to $\beta$-actin ( $n=6 /$ group, males aged 12 and 26 weeks). c-e Representative images of human postmortem AD brain hippocampal sections stained for ANXA1. Arrows indicate expression in neurons (c), microglia (d) and astrocytic (e) staining. Values shown in graphs represent the mean value \pm SEM and are expressed as fold change in comparison to the normalized control. Statistical analysis included Student's independent two-tailed $t$ test, ${ }^{*} p<0.05$

\section{hrANXA1 increases the expression and activity of $A \beta$-degrading enzyme neprilysin}

To understand the mechanism behind ANXA1's effect on reducing $A \beta$ levels in $N 2 a$ cells we investigated the effect of ANXA1 on A $\beta$ clearance. For this purpose, synthetic $\mathrm{A} \beta_{1-42}$ peptide $(0.1 \mu \mathrm{M})$ was added to the medium of N2asw cells over $48 \mathrm{~h}$ with or without $10 \mathrm{nM}$ hrANXA1 (Fig. 4a). In cells treated with hrANXA1, the levels of $A \beta_{1-42}$ synthetic peptide were reduced at faster rate compared with control cells (two-way ANOVA, effect of treatment $F(1,14)=11.60, p=0.0043$; effect of time $F(3,14)=64.71, p<0.0001$ ) (Fig. 4a). These results show that the stability of synthetic $A \beta$ peptide in the medium is affected in cells treated with hrANXA1.

We then examined whether stimulation with hrANXA1 induced an increase in enzymatic mechanisms of $A \beta$ degradation. The expression levels of $A \beta$-degrading enzymes, insulin-degrading enzyme (IDE) and neprilysin were assessed by Western blot. Interestingly, $2-\mu \mathrm{g} / \mathrm{ml}$ hrANXA1 treatment of N2asw cells led to a significant increase in neprilysin expression (Fig. 4b), which paralleled with higher neprilysin activity levels (Fig. 4c). This effect was partially reversed by the non-selective FPR inhibitor Boc1 ( $5 \mu \mathrm{g} / \mathrm{ml})$ (Fig. 4c), indicating that the effect might be mediated by the binding of ANXA1 to FPR receptors. Similar results were obtained in human SK-N-SH cells treated with $2-\mu \mathrm{g} / \mathrm{ml}$ hrANXA1, showing increased neprilysin expression, which was attenuated by the selective FPR2 inhibitor WRW4 (5 $\mu \mathrm{M})$ (Fig. 4d). We had previously proven the expression of FPR in both types of cells (Additional file 4: Figure S4C-D). This effect was associated with an increase in neprilysin transcription, with quantitative RT-PCR experiments showing higher neprilysin gene $(M M E)$ expression in SK-N-SH cells treated with $2 \mu \mathrm{g} / \mathrm{ml}$ hrANXA1 


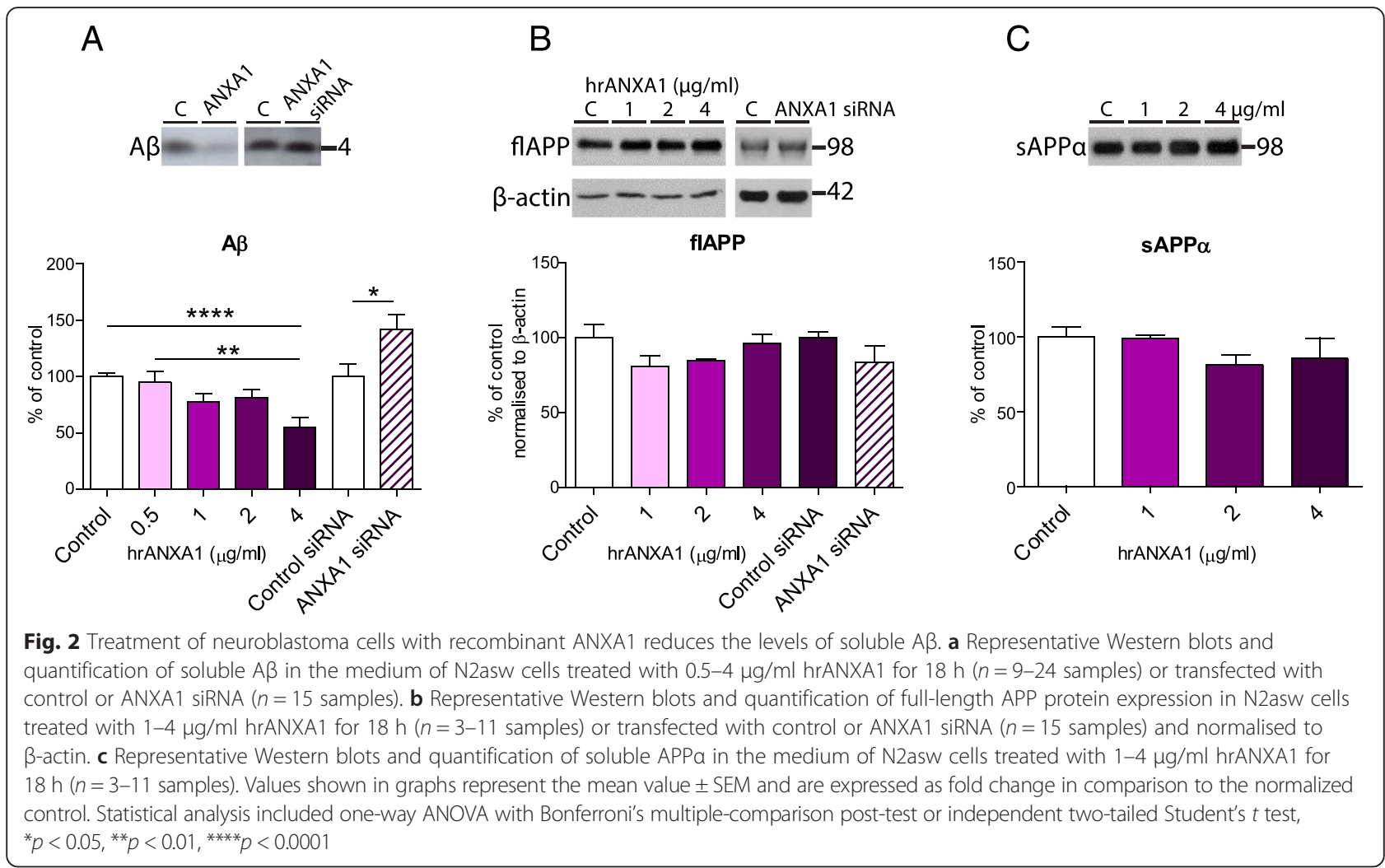

(Fig. 4e). The levels of IDE however were non-significantly altered by $2-4 \mu \mathrm{g} / \mathrm{ml}$ hrANXA1 treatment in both mouse N2asw (Fig. 4f) and human SK-N-SH cells (Fig. 4g).

\section{hrANXA1 increases microglial phagocytosis of $A \beta_{1-42}$}

Since microglia plays a crucial role in removing $A \beta_{1-42}$ and we have previously shown that ANXA1 has an important role in efferocytosis or phagocytosis/phagoapoptosis [12], we tested the effects of endogenous ANXA1 on microglial phagocytosis of $A \beta_{1-42}$ using fluorescently labelled $A \beta_{1-42}$ or scrambled $A \beta_{1-42}$ by FACS analysis. BV2 cells incubated with 5-FAM-labelled $A \beta_{1-42}(3 \mu \mathrm{g} /$ $\mathrm{ml}$ ) for $3 \mathrm{~h}$ in medium that had been conditioned by BV2 cells overnight (unchanged media) showed higher phagocytic activity compared to 5-FAM-labelled $A \beta_{1-42}$ $(3 \mu \mathrm{g} / \mathrm{ml}, 3 \mathrm{~h})$ added into fresh new media (Fig. 5a). This suggests that an endogenous molecule released by the microglia in unchanged media had a positive effect on enhancing $A \beta_{1-42}$ phagocytosis. The specificity of this observation was shown by the lack of effect of ANXA1 on the phagocytosis of scrambled $A \beta_{1-42}$. Since BV2 cells secrete ANXA1 into the supernatant [12], we next tested whether the factor released by microglia contributing to $A \beta_{1-42}$ phagocytosis was indeed ANXA1. For this reason, 5-FAM-labelled $A \beta_{1-42}$ phagocytosis was determined in BV2 cells with conditioned media including a neutralizing ANXA1 antibody $(20 \mathrm{ng} / \mathrm{ml})$ or IgG control antibody. The results in Fig. 5b show that treatment with anti-ANXA1-antibody-resulted in a reduction in 5FAM-labelled $A \beta_{1-42}$ phagocytosis, which was not detected with anti-IgG antibody control.

To further confirm the specificity of the effect of endogenous ANXA1 on $A \beta_{1-42}$ phagocytosis, we tested the effect of ANXA1 knockdown on microglial phagocytosis of 5-FAM-labelled A $\beta_{1-42}$. BV2 cells infected with shRNA lentivirus (wild type, PKCO, and shRNA ANXA1-clone 492) were incubated ( $3 \mathrm{~h}$ ) with 5-FAM-labelled $\mathrm{A} \beta_{1-42}$ (5 $\mu \mathrm{g} / \mathrm{ml})$, and phagocytosis was measured using an imaging flow cytometer (ImageStream). The efficiency of the shRNA infection is shown in Additional file 1: Figure S1. As illustrated in Fig. 5c, the phagocytosis of 5-FAMlabelled $A \beta_{1-42}$ was significantly reduced in ANXA1 knockdown cells in comparison to control BV2 cells and mock-infected BV2 cells. The representative histograms of image-based cytometry analysis of 5-FAM-labelled A $\beta_{1-42}$ phagocytosis are shown in Additional file 3: Figure S3D.

Furthermore, we investigated the pharmacological effect of ANXA1 on $A \beta_{1-42}$ phagocytosis, and BV2 cells were pre-incubated with $5 \mu \mathrm{g} / \mathrm{ml}$ of hrANXA1 $30 \mathrm{~min}$ prior to incubation with 5-FAM-labelled $A \beta_{1-42}$. Results presented in Fig. $5 \mathrm{c}$ show clearly the ability of the recombinant molecule to stimulate the phagocytosis 


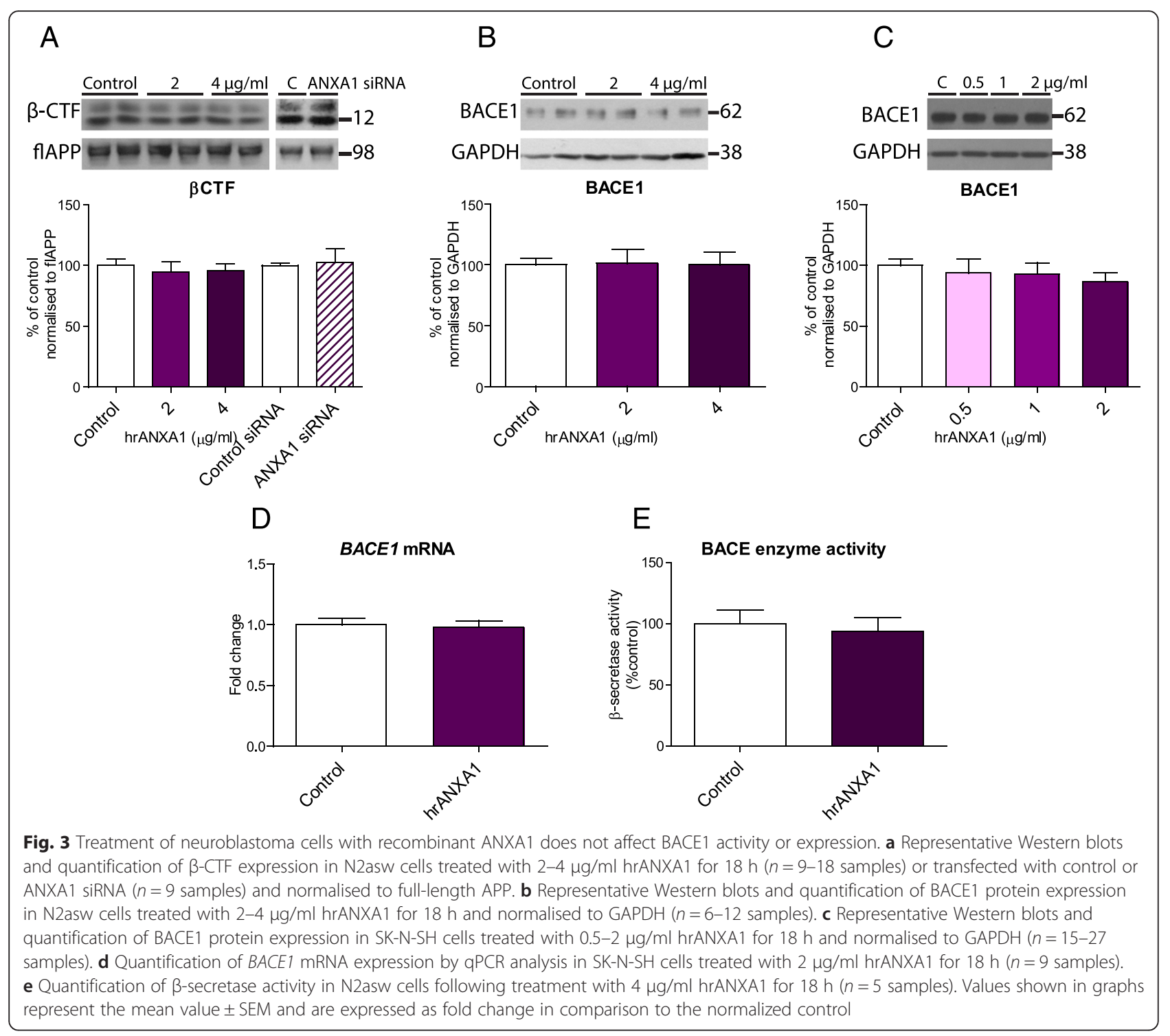

of 5-FAM-labelled $A \beta_{1-42}$, further supporting our hypothesis that ANXA1 stimulates the uptake of $A \beta_{1-}$ 42 in a non-phlogistic manner.

Next, we explored the involvement of FPR2 on the ANXA1-mediated increase on $A \beta_{1-42}$ phagocytosis. BV2 cells were pre-incubated with WRW4, a specific antagonist of FPR2, 20 min prior to incubation with hrANXA1. The pharmacological blockage of FPR2 clearly reversed the ANXA1-mediated effect on $A \beta_{1-42}$ phagocytosis (Fig. $5 \mathrm{c}$ ), suggesting that ANXA1 affects microglial phagocytosis of $A \beta_{1-42}$ by a mechanism dependent on the activation of FPR2 (two-way ANOVA, interaction $F(6,41)=23.04, p<0.0001$; effect of cell line $F(2,41)=13.65, p<0.0001$; effect of treatment $F(3,41)=95.70, p<0.0001$.

Additionally, and in order to determine if the effect of ANXA1 on microglial phagocytosis was mediated through changes in the expression of microglial receptors involved in receptor-mediated endocytosis, we measured the expression of a variety of these receptors, including the receptor for advanced glycation end-products (RAGE), the scavenger receptor macrophage receptor with collagenous structure (MARCO) and FPR in BV2 cells. Although the expression of these receptors seemed to be modified by incubation with synthetic $A \beta$, the effects were not reversed or modified by ANXA1 treatment (Fig. $5 \mathrm{~d}-\mathrm{f}$ ).

\section{ANXA1 reduces the $A \beta$-induced expression of pro-inflammatory cytokines in microglia}

It is widely accepted that exposure of microglial cells to $\mathrm{A} \beta$ induces an inflammatory response, characterised by the secretion of cytokines and other pro-inflammatory molecules (see review [2]). Since ANXA1-mediated phagocytosis should work in a non-phlogistic manner, 


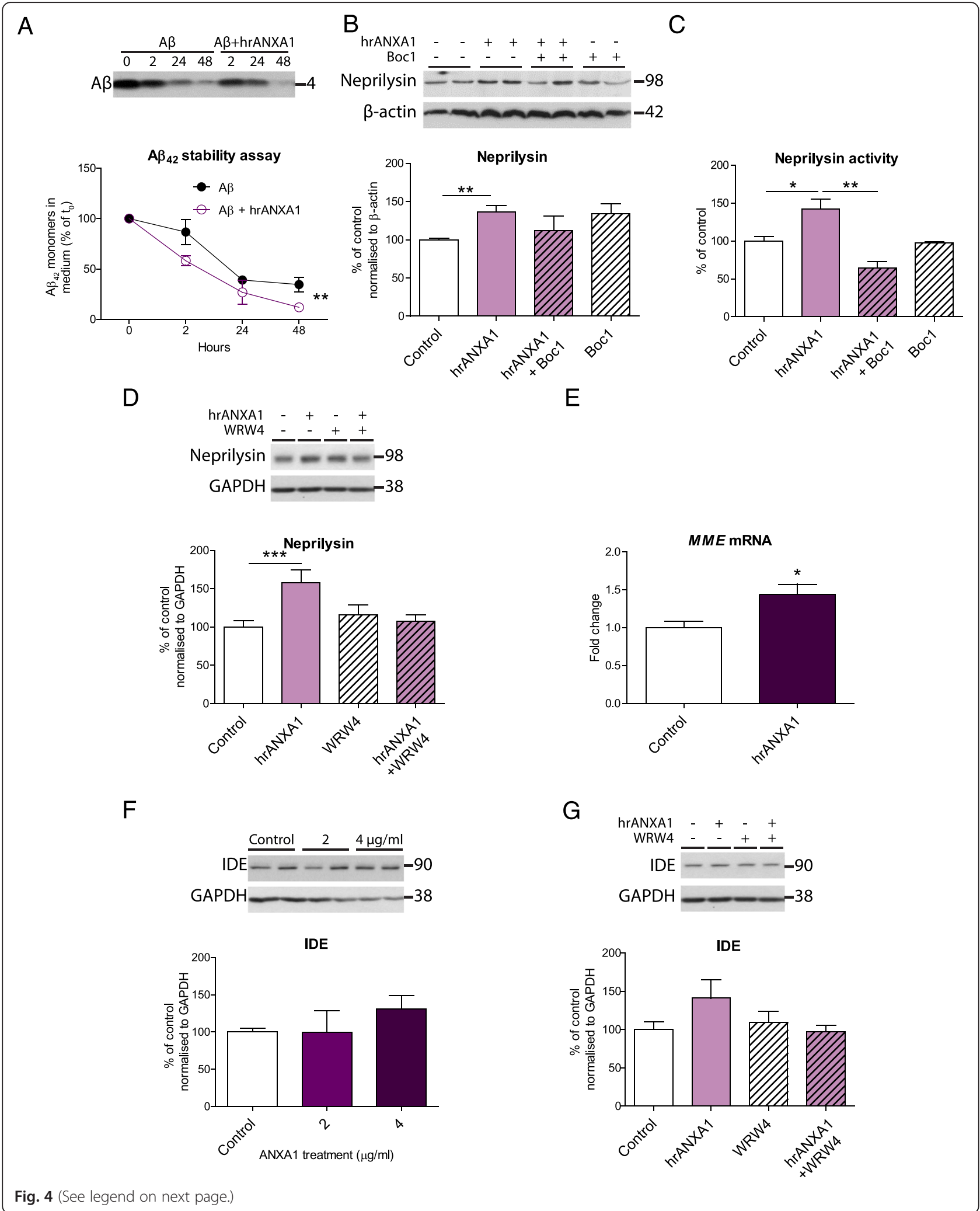


(See figure on previous page.)

Fig. 4 hrANXA1 treatment increases the expression and activity of A -degrading enzyme neprilysin. a Representative Western blots and quantification of synthetic $A \beta_{1-42}$ monomers expression in the medium of N2asw cells incubated with synthetic $A \beta_{1-42}(0.1 \mu M)$, following $0-48-h$ treatment with 10-nM hrANXA1 assessed by Western blotting using $6 \mathrm{E} 10$ antibody $(n=3)$. b Representative Western blots and quantification of neprilysin protein expression in N2asw cells treated with $4 \mu \mathrm{g} / \mathrm{ml}$ hrANXA1 and/or the non-selective FPR inhibitor Boc1 $(5 \mu \mathrm{g} / \mathrm{ml})$ for $18 \mathrm{~h}$, normalised to $\beta$-actin ( $n=10-37$ samples). c Quantification of neprilysin activity in N2asw cells treated with $4 \mu \mathrm{g} / \mathrm{ml}$ hrANXA1 and/or the non-selective FPR inhibitor Boc1 (5 $\mathrm{\mu g} / \mathrm{ml})$ for $18 \mathrm{~h}$ ( $n=2-8$ samples). d Representative Western blots and quantification of neprilysin protein expression in SK-N-SK cells treated with $2 \mu \mathrm{g} / \mathrm{ml}$ hrANXA1 and/or selective FPR2 inhibitor WRW4 $(5 \mu \mathrm{M})$ for $18 \mathrm{~h}$ normalised to GAPDH ( $n=11-21$ samples). e Quantification of MME (neprilysin) mRNA expression by qPCR analysis in SK-N-SK cells treated with $2 \mu \mathrm{g} / \mathrm{ml}$ hrANXA1 for $18 \mathrm{~h}$ ( $n=5-6$ samples). f Representative Western blots and quantification of IDE protein expression in N2asw cells treated with 2-4 $\mu \mathrm{g} / \mathrm{ml}$ hrANXA1 for $18 \mathrm{~h}$ and normalised to GAPDH. g Representative Western blots and quantification of IDE protein expression in SK-N-SK cells treated with $2 \mu \mathrm{g} / \mathrm{ml}$ hrANXA1 and/or selective FPR2 inhibitor WRW4 (5 $\mu$ M) for $18 \mathrm{~h}$, normalised to GAPDH ( $n=10-18$ samples). Values shown in graphs represent the mean value \pm SEM and are expressed as a percentage change in comparison to the normalized control or fold change of control. Statistical analysis included two-way ANOVA, one-way ANOVA with Bonferroni's multiple-comparison post-test, Kruskal-Wallis test with Dunn's multiple-comparison post-test or unpaired Student's two-tailed $t$ test as appropriate, ${ }^{*} p<0.05,{ }^{* *} p<0.01,{ }^{* * *} p<0.001$

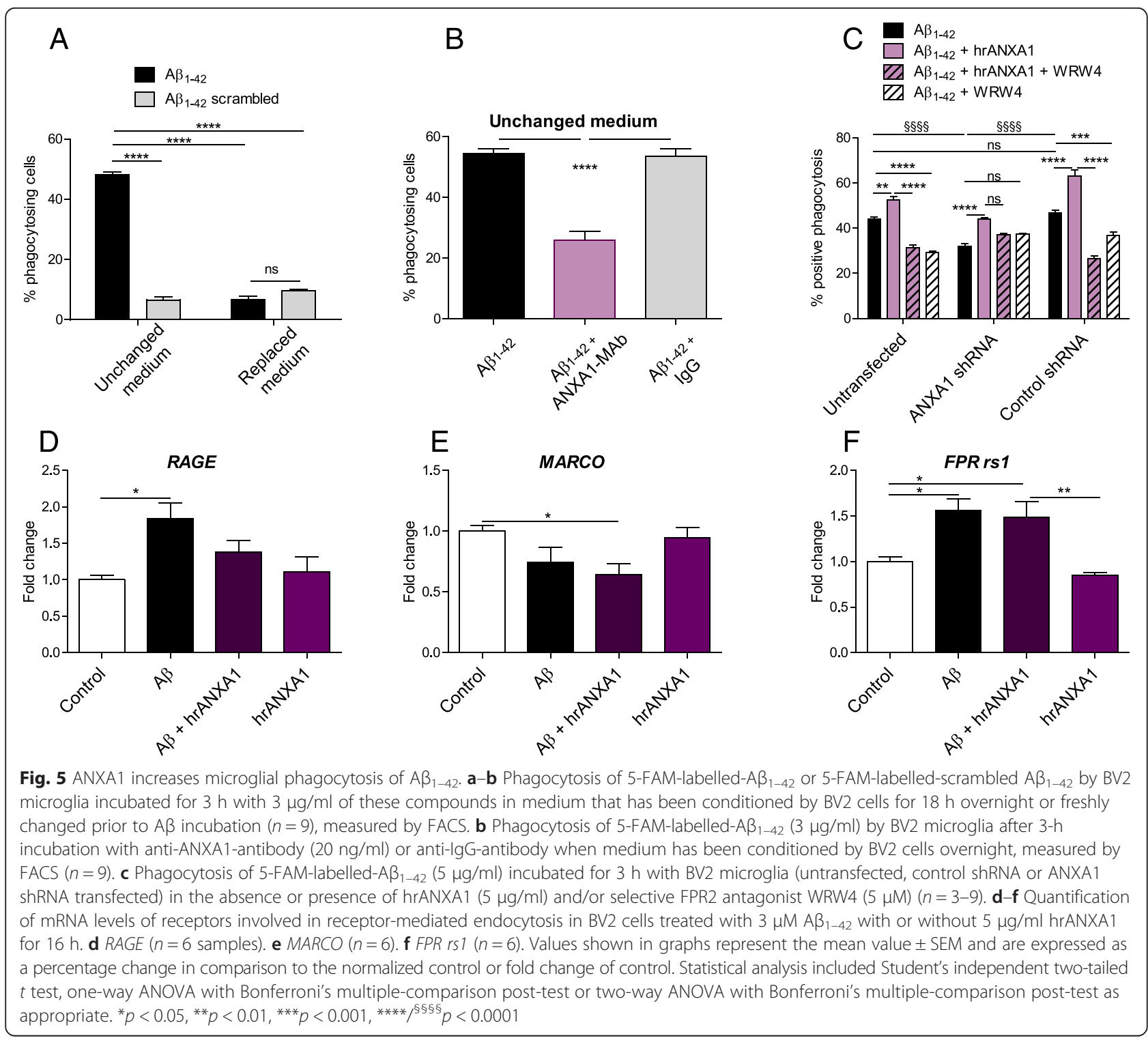


we measured the expression of pro- and anti-inflammatory mediators released during BV2 incubation with synthetic A $\beta_{1-42}$. The levels of IL6 (Il6) (Fig. 6a), TNF $\alpha$ (Tnf) (Fig. 6b) and IL4 (Il4) (Fig. 6c) mRNAs were found increased in BV2 cells activated by synthetic $A \beta_{1-42}$, and the expression of $I l 6$ and $\operatorname{Tnf}$ was clearly reduced by incubation with recombinant ANXA1. Conversely, the anti-inflammatory arginase-1 (Arg1), IL10 (Il10) and TGF- $\beta 1$ (Tgfb1) were reduced by incubation with $A \beta_{1-42}$ (Fig. $6 \mathrm{~d}-\mathrm{f}$ ), and only $T g f b 1$ levels were restored after exposure to hrANXA1 (Fig. 6f). Therefore, these results support the antiinflammatory role of ANXA1 in reversing the inflammatory response induced by $A \beta$ in microglia.

\section{Discussion}

During the last decade, ANXA1 has gained interest as a potential pharmacological tool for the treatment of neurodegenerative disorders, including multiple sclerosis [14], stroke [31] and Parkinson's disease [32]. Previously, we reported that ANXA1 expression is increased in microglia in close proximity to $A \beta$ plaques using $A D$ postmortem brain tissue [12]. In the present study, we demonstrate that brains of $\mathrm{AD}$ patients and a murine transgenic model of amyloidosis express higher levels of ANXA1, not only in microglia but also in astrocytes and neurons. The increases in ANXA1 observed in AD brains suggest that upregulation of ANXA1 could represent an adaptive response of microglia during inflammatory conditions and an attempt of the system to calm down the inflammation at early stages of the disease, since ANXA1 effectively solves the phase of inflammation. However, this was not observed in older animals with more severe AD pathology. This is in agreement with evidence reported in animal models of AD demonstrating that at early stages of the disease, glial cells may have a neuroprotective phenotype, secreting antiinflammatory molecules $[33,34]$ and increasing $A \beta$ phagocytosis. However, in later stages with chronic production of $\mathrm{A} \beta$ and pro-inflammatory cytokines, microglia change their neuroprotective phenotype in favour of a more pro-inflammatory activation state through the release of cytokines and chemokines. Interestingly, we found that the differential expression of ANXA1 in 5XFAD mice seemed to correlate with the levels of pro-
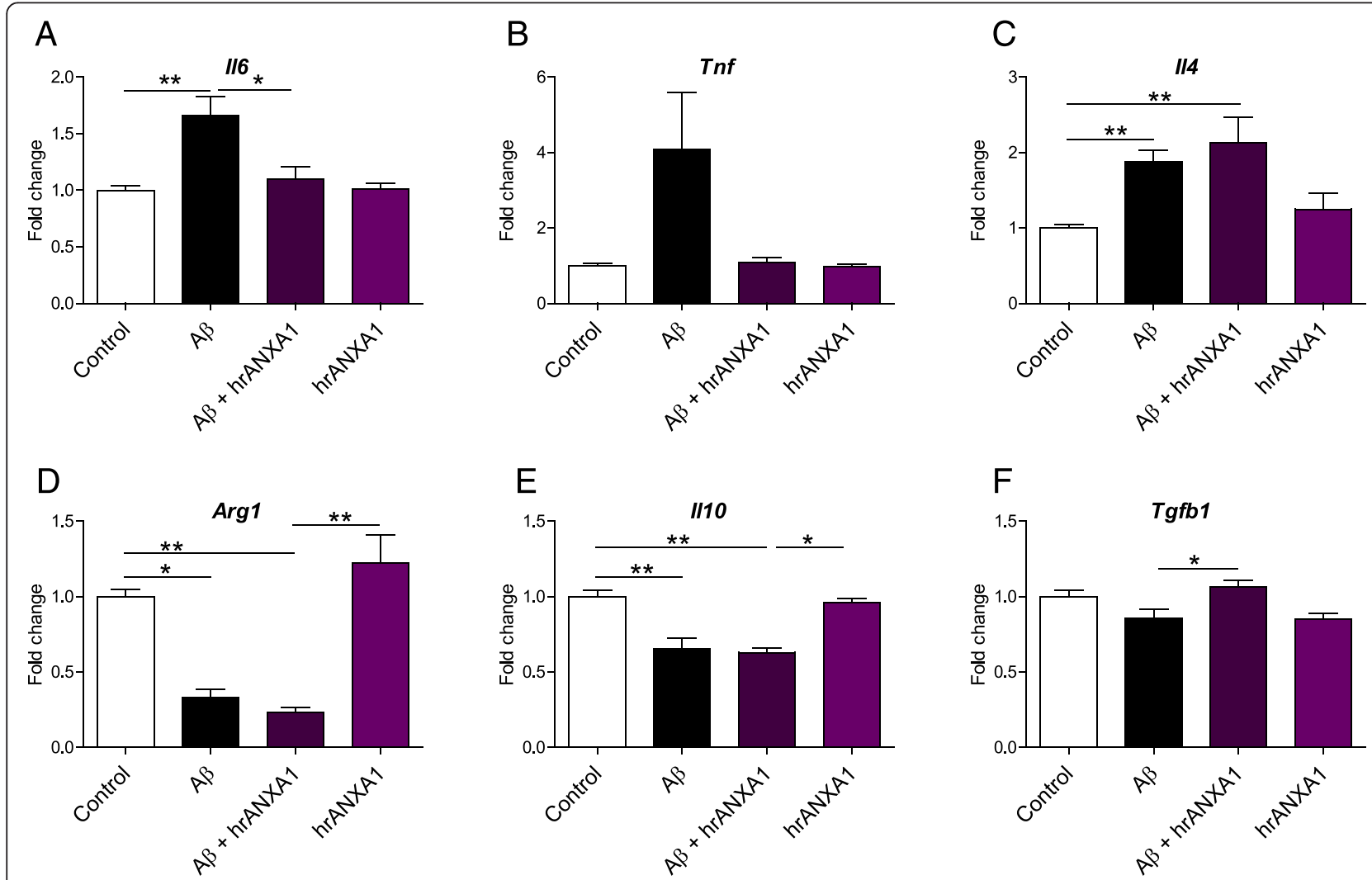

Fig. 6 ANXA1 reduces the A $\beta$-induced expression of pro-inflammatory mediators in microglia. Quantification of mRNA levels of inflammatory mediators in BV2 cells treated with $3 \mu \mathrm{M} \mathrm{A} \beta_{1-42}$ with or without $5 \mu \mathrm{g} / \mathrm{ml}$ hrANXA1 for $16 \mathrm{~h}$. a $1 / 6(n=6-12$ samples). b Tnf $(n=6-17)$. c $\| 4$ ( $n=6-9$ samples). d Arg1 ( $n=6-9$ samples). e 1110 ( $n=6-14$ samples). $\mathbf{f}$ Tgfb1 ( $n=6$ samples). Values shown in graphs represent the mean value \pm SEM and are expressed as fold change in comparison to the normalized control. Statistical analysis included one-way ANOVA with Bonferroni's multiple-comparison post-test or Kruskal-Wallis test with Dunn's multiple-comparison post-test, ${ }^{*} p<0.05,{ }^{* *} p<0.01$ 
inflammatory cytokines IL-6 and TNF $\alpha$ (Additional file 5: Figure $\mathrm{S} 5 \mathrm{E}, \mathrm{F}$ ) and not with the expression of $\mathrm{A} \beta$ (Additional file 5: Figure S5G,H) or FPR (Additional file 5: Figure S5A-C). Therefore, our results indicate that the increases in ANXA1 appear to be more related to the inflammatory response following $A \beta$ deposition rather than the levels of $A \beta$ in the brain.

Since ANXA1 was expressed in neurons from AD patients, we investigated the in vitro effects of ANXA1 on $A \beta$ generation and degradation using a neuronal cell line. We found that ANXA1 seems to be involved in the degradation of $A \beta$ by neuronal cells by inducing the expression of neprilysin. Neprilysin (NEP), also known as CALLA (common acute lymphocytic leukaemia (ALL) antigen), enkephalinase, neutral endopeptidase 24.11, membrane metalloendopeptidase (MME) and CD10 antigen [35-37], belongs to the family of M13 zincmetalloendopeptidases [38]. In the brain, NEP is considered a major amyloid-degrading enzyme [39] and is mainly located on neuronal cells, especially in the striatonigral pathway [40, 41]. In addition, it is involved in other important neuronal functions, cleaving substrates such as substance P, met- and leu-enkephalin, FMLP, the bombesin-like peptides, atrial natriuretic factor, endothelin and oxytocin [39]. Its regulation and reactivation have been extensively studied in the last decade. Factors that affect NEP expression often differ between neural and non-neural tissues as there are several NEP mRNAs which show cell- and tissue-specific expression [42]. In neurons, the neuropeptide somatostatin [43] and vitamin $\mathrm{D}$ are able to upregulate NEP activity [44]. Recently, it was shown that the APP intracellular domain (AICD) fragment derived from the $\gamma$-secretase cleavage of APP was also able to regulate the transcription of NEP [45]. Expression of the NEP gene is controlled through two distinct promoters [46] whose role differs between cell types, although both promoters show similar characteristics and activity. Interestingly, our study suggests that incubation of neuroblastoma cells with recombinant ANXA1 lead to an increase in NEP expression and this effect was reversed by FPR2 inhibitors. These results suggest that FPRL1/FPR2 activation by ANXA1 can regulate NEP expression, although this hypothesis needs to be further confirmed by experiments in FPRL1/FPR2 knockout cells. Similar to somatostatin receptors, FPR receptors are $\mathrm{G}$ protein-coupled receptors, which upon activation, trigger several agonist-dependent signal transduction pathways [47]. We do not rule out that ANXA1 could affect $A \beta$ degradation by alternative mechanisms that do not involve FPRL1/FPR2 activation. ANXA1 can bind phospholipids in cellular membranes in a dynamic and reversible fashion in a $\mathrm{Ca}^{2+}$-dependent manner. This interaction can affect $\mathrm{Ca}^{2+}$ signalling and allows ANXA1 to contribute to the organization of membrane domains or signalling platforms and the formation of complex protein networks [48].

Additionally, we demonstrate that recombinant ANXA1 increases $A \beta$ uptake in microglial BV2 cells and that its knockdown reduces $A \beta$ phagocytosis. This result is in agreement with the data from Yona et al. (2006), who reported that lack of ANXA1 leads to reduced phagocytosis in ANXA1 knockout cells in the peripheral nervous system [49]. The presence of ANXA1 on the phagosomal membrane appears to be functionally important in macrophages and neutrophils. It seems, however, that the effects are more specific for $A \beta_{42}$ than for any particle, since the phagocytosis of the scrambled $A \beta$ peptide was less affected by ANXA1. It is well accepted that $\mathrm{A} \beta_{1-42}$ binds to FPRL1/FPR2 and is rapidly internalised into the cytoplasmic compartment of phagocytic cells [50]. Branderburg et al. (2008) have shown that the A $\beta / F P R L 1$ complex co-localises with clathrin-coated endocytotic vesicles, and the activation of phospholipase D (PLD) seems to play an important role in the internalization of the $A \beta / F P R L 1$ complex $[51,52]$. In addition, FPRL1/FPR2 can interact with scavenger receptors in glial cells and this association has been reported to be important for $A \beta_{1-42}$-mediated signal transduction [53]. One potential mechanism by which ANXA1 could affect $A \beta$ endocytosis includes the interaction of ANXA1 with the actin cytoskeleton [54]. ANXA1 binds to and bundles F-actin in vitro and co-localises with F-actin in different cell lines $[14,55]$. In vitro studies have shown that ANXA1 facilitates the interaction between F-actin and phagosomes on macrophages, whereas the knockdown of ANXA1 expression resulted in impaired phagocytosis [54]. Our results suggest that the interaction between ANXA1 and FPRL1/FPR2 is functionally important to the formation of the phagosomal membrane on microglia and $A \beta$ phagocytosis.

In addition to the effect of ANXA1 on $A \beta$ phagocytosis, we have shown that ANXA1 was able to reverse the pro-inflammatory effects of $A \beta_{1-42}$ on microglia by regulating the genetic expression of $I l 6, T n f$ and $T g f b 1$. These results are in agreement with a previous study from our group showing that ANXA1 was able to reverse the LPS-induced activation of microglia [12]. Moreover, macrophages from mice lacking ANXA1 showed higher levels of TNF $\alpha$ and IL- 6 in response to LPS [56]. These results confirm that ANXA1 regulates microglial activation in response to inflammatory stimuli.

\section{Conclusions}

Our data support a potential role of ANXAl in AD by reducing $A \beta$ levels and decreasing neuroinflammation, suggesting a novel view that ANXAl may play a protective role in $\mathrm{AD}$ progression. We have shown in this study 
that ANXA1 affects the degradation and clearance of $A \beta$ and propose ANXA1 as a promising therapeutic tool in AD. However, in spite of the protective role of ANXA1 in $A D$, more studies should be conducted in order to clarify possible regulatory mechanisms in this resolution pathway, which may affect its functionality in different stages of the disease.

\section{Additional files}

Additional file 1: Figure S1. Efficiency of ANXA1 shRNA infection in BV2 cells. Representative Western blot image showing protein expression of ANXA1 in BV2 cells infected with control shRNA, and ANXA1 shRNA_clones 492A, 492B, 495A and 495B. Band intensities were determined using ImageJ and normalised to tubulin. (PDF $99 \mathrm{~kb}$ )

Additional file 2: Supplementary methods. (DOC $22 \mathrm{~kb}$ )

Additional file 3: Figure S3. ImageStream quantification of 5-FAMlabelled $A \beta_{1-42}$ phagocytosis by BV2 cells. Histogram showing gating of BV2 cells. B. Scatterplot showing gating of focused BV2 cells. C. Histogram and representative images of negative and positive 5-FAM-labelled $A \beta_{1-42}$ phagocytosis by BV2 cells. D. Representative histograms of 5-FAM-labelled $A \beta_{1-42}$ phagocytosis by BV2 cells (WT, control shRNA and shRNA ANXA1) incubated for $3 \mathrm{~h}$ with 5-FAM-labelled $A \beta_{1-42}(5 \mu \mathrm{g} / \mathrm{ml})$ added to BV2-conditioned medium. (PDF $865 \mathrm{~kb}$ )

Additional file 4: Figure S4. Expression of FPRL1/FPR2 in human and mouse samples and in N2asw, SK-N-SH and BV2 cell lines. A. Representative Western blots and quantification of FPRL1/FPR2 protein expression in the frontal cortex of neurologically healthy controls and sporadic Alzheimer's patients and normalised to $\beta$-actin ( $n=5$ controls, 3 males, 2 females, range 81-97 years, mean age $86.8 \pm 3$ years, $n=7$ AD cases, 3 males, 4 females, range $83-98$ years, mean age $91.3 \pm 2$ years). B. Representative blots and quantification of FPRL1/FPR2 expression in the cortex of 5XFAD mice and wild-type littermates and normalised to $\beta$-actin ( $n=6 /$ group, males aged 12 and 26 weeks). C-E. Histograms showing mean intensity fluorescence (FL1) of FPRL1/FPR2 expression (red line) on (C) N2asw, (D) SK-N-SH and (E) BV2 cells analysed by FACS. Black lines shows FL1 of N2asw, SK-N-SH and BV2 cells incubated with goat anti-rabbit FITC-conjugated IgG. Values shown in graphs represent the mean value \pm SEM and are expressed as fold change in comparison to the normalized control. (PDF $1076 \mathrm{~kb}$ )

Additional file 5: Figure S5. Correlation of ANXA1 expression with FPR cytokines and $A \beta$. A. Scatterplot showing relationship between FPRL1/ FPR2 and ANXA1 protein expression assessed by Western blotting in the frontal cortex of neurologically healthy controls and sporadic Alzheimer's patients ( $n=5$ controls, 3 males, 2 females, range 81-97 years, mean age $86.8 \pm 3$ years; $n=7$ AD cases, 3 males, 4 females, range 83-98 years, mean age $91.3 \pm 2$ years). B. Scatterplot showing relationship between FPRL1/FPR2 and ANXA1 protein expression assessed by Western blotting in the motor cortex of 5XFAD mice and wild-type littermates and $(n=6 /$ group, males aged 12 and 26 weeks). C. Scatterplot showing relationship between FPR rs1 and ANXA1 mRNA expression assessed in the frontal cortex of 5XFAD mice and wild-type littermates by GPCR $(n=19$, males aged 12 and 26 weeks). D. Scatterplot showing relationship between ANXA1 protein expression assessed by Western blotting and TNFa expression measured by ELISA in in the frontal cortex of neurologically healthy controls and sporadic Alzheimer's patients $(n=8$ controls, 5 males, 3 females, range $40-82$ years, mean age $67.1 \pm 6$ years; $n=10 \mathrm{AD}$ cases, 7 males, 3 females, range $42-98$ years, mean age $72.5 \pm 6$ years). E. Scatterplot showing relationship between Tnf and ANXA1 mRNA expression assessed in the frontal cortex of 5XFAD mice and wild-type littermates by gPCR $\left(n=18\right.$, males aged 12 and 26 weeks). ${ }^{* * *} p<0.001, r^{2}=0.5779$. F. Scatterplot showing relationship between 116 and ANXA1 mRNA expression assessed in the frontal cortex of 5XFAD mice and wild-type littermates by qPCR $\left(n=19\right.$, males aged 12 weeks and 26 weeks). ${ }^{* * * *} p<0.0001, r^{2}=0.6352$. G. Scatterplot showing relationship between ANXA1 protein expression assessed by Western blotting and $A \beta_{1-40}$ expression measured by ELISA in the frontal cortex of neurologically healthy controls and sporadic Alzheimer's patients ( $n=10$ controls, 6 males, 4 females, range 40-97 years, mean age $71.5 \pm 6$ years; $n=12$ AD cases, 8 males, 4 females, range $42-98$ years, mean age $74.4 \pm 5$ years). $H$. Scatterplot showing relationship between $A \beta$ and ANXA1 protein expression assessed by Western blotting in the cortex of 5XFAD mice ( $n=11$, males aged 12 and 26 weeks). (PDF $111 \mathrm{~kb}$ )

\section{Acknowledgements}

We would like to thank the London Neurodegenerative Diseases Brain Bank and the Swedish Brain Bank for the donation of the human brains used in the present study.

\section{Funding}

This study was partially funded by the Imperial College Medical Research Council Doctoral Training Centre (studentship to MR). RAL fellow was sponsored from CAPES Foundation, Ministry of Education, Brazil (grant\#7326/2014-09). ES research is supported by FISM-Fondazione Italiana Sclerosi Multipla-cod 2014/R/21.

\section{Availability of data and materials}

Materials described in the manuscript, including all relevant raw data, will be freely available to any scientist wishing to use them for non-commercial purposes, without breaching participant confidentiality. Data will be available upon request.

All data generated or analysed during this study are included in this published article (and its supplementary information files).

\section{Authors' contributions}

MR carried out the analysis of ANXA1 expression in humans and of APP processing in N2a cells, the qPCR analysis, prepared the final figures and participated in the draft of the manuscript; UNS performed the neprilysin activity and expression assays in N2a cells; SG coordinated the

immunohistochemistry in humans; RL performed the phagocytosis studies in BV2 cells and prepared the figures on phagocytosis; ES participated in the design and conception of the study, coordinated the phagocytosis studies, wrote the phagocytosis results and revised the manuscript critically for important intellectual content; MS coordinated the expression analysis of proteins and genes related to APP processing and cytokines in cells and AD brains, participated in the design and conception of the study, performed the experiments and wrote the manuscript. All authors read and approved the final manuscript.

\section{Competing interests}

The authors declare that they have no competing interests.

\section{Consent for publication}

This publication does not contain any individual person's data, therefore, is not applicable.

\section{Ethics approval and consent to participate}

Human brains were obtained from routine autopsies at the London Neurodegenerative Diseases Brain Bank at King's College London and the Swedish Brain Bank in accordance with laws and the permission of the ethical committees. Both brain banks belong to the BrainNet Europe (BNE) consortium, a consortium of 19 European brain banks, who have drafted an ethical Code of Conduct for brain banking that covers basic legal rules and bioethical principles involved in brain banking. Sources include laws, regulations and guidelines (Declarations, Conventions, Recommendations, Guidelines and Directives) issued by international key organizations, such as the Council of Europe, European Commission, World Medical Association and World Health Organization.

All animal procedures were approved by the UK Home Office and were in accordance with the Animals (Scientific Procedures) Act of 1986. The Home office project licence used was PPL 70/7485.

Received: 18 March 2016 Accepted: 20 August 2016 Published online: 02 September 2016

\section{References}

1. Haass C, Kaether C, Thinakaran G, Sisodia S. Trafficking and proteolytic processing of APP. Cold Spring Harb Perspect Med. 2012;2:a006270. 
2. Solito E, Sastre M. Microglia function in Alzheimer's disease. Front Pharmacol. 2012;3:14.

3. Perry VH, Teeling J. Microglia and macrophages of the central nervous system: the contribution of microglia priming and systemic inflammation to chronic neurodegeneration. Semin Immunopathol. 2013;35:601-12.

4. Sastre M, Klockgether T, Heneka MT. Contribution of inflammatory processes to Alzheimer's disease: molecular mechanisms. Int J Dev Neurosci. 2006;24:167-76.

5. Sastre M, Dewachter I, Landreth GE, Willson TM, Klockgether T, van Leuven F, et al. Nonsteroidal anti-inflammatory drugs and peroxisome proliferatoractivated receptor-gamma agonists modulate immunostimulated processing of amyloid precursor protein through regulation of beta-secretase. J Neurosci. 2003:23:9796-804.

6. Sastre M, Dewachter I, Rossner S, Bogdanovic N, Rosen E, Borghgraef P, et al. Nonsteroidal anti-inflammatory drugs repress $\beta$-secretase gene promoter activity by the activation of PPARY. Proc Natl Acad Sci U S A. 2006;103:443-8

7. Birch AM, Katsouri L, Sastre M. Modulation of inflammation in transgenic models of Alzheimer's disease. J Neuroinflammation. 2014;11:25.

8. Frautschy SA, Yang F, Irrizarry M, Hyman B, Saido TC, Hsiao K, et al. Microglial response to amyloid plaques in APPsw transgenic mice. Am J Pathol. 1998;152:307-17.

9. Qiu WQ, Ye Z, Kholodenko D, Seubert P, Selkoe DJ. Degradation of amyloid $\beta$-protein by a metalloprotease secreted by microglia and other neural and non-neural cells. J Biol Chem. 1997;272:6641-6

10. Parente L, Solito E. Annexin 1: more than an anti-phospholipase protein. Inflamm Res. 2004;53:125-32.

11. Perretti $M, D^{\prime}$ Acquisto $F$. Annexin $A 1$ and glucocorticoids as effectors of the resolution of inflammation. Nat Rev Immunol. 2009;9:62-70.

12. McArthur S, Cristante E, Paterno M, Christian H, Roncaroli F, Gillies GE, et al. Annexin A1: a central player in the anti-inflammatory and neuroprotective role of microglia. J Immunol. 2010;185:6317-28.

13. Solito E, MCArthur S, Christian H, Gavins F, Buckingham JC, Gillies GE. Annexin A1 in the brain-undiscovered roles? Trends Pharmacol Sci. 2008;29:135-42.

14. Cristante E, McArthur S, Mauro C, Maggioli E, Romero IA, Wylezinska-Arridge $M$, et al. Identification of an essential endogenous regulator of blood-brain barrier integrity, and its pathological and therapeutic implications. Proc Natl Acad Sci U S A. 2013;110:832-41.

15. Young KA, Hirst WD, Solito E, Wilkin GP. De novo expression of lipocortin-1 in reactive microglia and astrocytes in kainic acid lesioned rat cerebellum. Glia. 1999;26:333-43.

16. Lim LH, Solito E, Russo-Marie F, Flower RJ, Perretti M. Promoting detachment of neutrophils adherent to murine postcapillary venules to control inflammation: effect of lipocortin 1. Proc Natl Acad Sci U S A. 1998;95:14535-9.

17. Perretti M, Ingegnoli F, Wheller SK, Blades MC, Solito E, Pitzalis C. Annexin 1 modulates monocyte-endothelial cell interaction in vitro and cell migration in vivo in the human SCID mouse transplantation model. J Immunol. 2002;169:2085-92.

18. Solito E, Romero IA, Marullo S, Russo-Marie F, Weksler BB. Annexin 1 binds to U937 monocytic cells and inhibits their adhesion to microvascular endothelium: involvement of the alpha 4 beta 1 integrin. J Immunol. 2000;165:1573-81.

19. Yona S, Buckingham JC, Perretti M, Flower RJ. Stimulus-specific defect in the phagocytic pathways of annexin 1 null macrophages. $\mathrm{Br} J$ Pharmacol. 2004;142:890-8.

20. Flower R. Lipocortin and the mechanism of action of the glucocorticoids. Br J Pharmacol. 1988;94:987-1015.

21. Hannon R, Croxtall JD, Getting SJ, Roviezzo F, Yona S, Paul-Clark MJ, et al. Aberrant inflammation and resistance to glucocorticoids in annexin 1-/- mouse. FASEB J. 2003;17:253-5.

22. Buckingham JC, John CD, Solito E, Tierney T, Flower RJ, Christian $\mathrm{H}$, et al. Annexin 1, glucocorticoids, and the neuroendocrine-immune interface. Ann N Y Acad Sci. 2006;1088:396-409.

23. Bouwmeester $T$, Bauch A, Ruffner $H$, Angrand P, Bergamini $G$, Croughton $K$, et al. A physical and functional map of the human TNF-a/NF-kB signal transduction pathway. Nat Cell Biol. 2004;6:97-105.

24. Heurtaux T, Michelucci A, Losciuto S, Gallotti C, Felten P, Dorban G, et al. Microglial activation depends on beta-amyloid conformation: role of the formylpeptide receptor 2. J Neurochem. 2010;114:576-86.
25. Walther A, Riehemann K, Gerke V. A novel ligand of the formyl peptide receptor: annexin I regulates neutrophil extravasation by interacting with the FPR. Mol Cell. 2000;5:831-40.

26. Le Y, Gong W, Tiffany HL, Tumanov A, Nedospasov S, Shen W, et al. Amyloid $B 42$ activates a G-protein-coupled chemoattractant receptor, FPR-like-1. J Neurosci. 2001;21:RC123.

27. Pan X, Zhu Y, Lin N, Zhang J, Ye Q, Huang H, et al. Microglial phagocytosis induced by fibrillar $\beta$-amyloid is attenuated by oligomeric $\beta$-amyloid: implications for Alzheimer's disease. Mol Neurodegener. 2011;6:1-18.

28. Oakley H, Cole SL, Logan S, Maus E, Shao P, Craft J, et al. Intraneuronal beta-amyloid aggregates, neurodegeneration, and neuron loss in transgenic mice with five familial Alzheimer's disease mutations: potential factors in amyloid plaque formation. J Neurosci. 2006;26:10129-40.

29. Maggioli E, McArthur S, Mauro C, Kieswich J, Kusters D, Reutelingsperger C, et al. Estrogen protects the blood-brain barrier from inflammation-induced disruption and increased lymphocyte trafficking. Brain Behav Immun. 2016;51:212-22.

30. Katsouri L, Parr C, Bogdanovic N, Willem M, Sastre M. PPARy co-activator-1a (PGC-1a) reduces amyloid- $\beta$ generation through a PPARY-dependent mechanism. J Alzheimers Dis. 2011;25:151-62.

31. Gavins FN, Dalli J, Flower RJ, Granger DN, Perretti M. Activation of the annexin 1 counter-regulatory circuit affords protection in the mouse brain microcirculation. FASEB J. 2007;21:1751-8.

32. Knott C, Stern G, Wilkin G. Inflammatory regulators in Parkinson's disease: iNOS, lipocortin-1, and cyclooxygenases-1 and-2. Mol Cell Neurosci. 2000;16:724-39.

33. Hickman SE, Allison EK, El Khoury J. Microglial dysfunction and defective beta-amyloid clearance pathways in aging Alzheimer's disease mice. J Neurosci. 2008;28:8354-60.

34. Jimenez S, Baglietto-Vargas D, Caballero C, Moreno-Gonzalez I, Torres M, Sanchez-Varo R, et al. Inflammatory response in the hippocampus of PS1M146L/APP751SL mouse model of Alzheimer's disease: age-dependent switch in the microglial phenotype from alternative to classic. J Neurosci. 2008;28:11650-61.

35. Brown G, Greaves MF, Lister T, Rapson N, Papamichael M. Expression of human $T$ and B lymphocyte cell-surface markers on leukaemic cells. Lancet. 1974;304:753-5.

36. Schwartz JC, de la Baume S, Malfroy B, Patey G, Perdrisot R, Swerts JP, et al. "Enkephalinase", a newly characterised dipeptidyl carboxypeptidase: properties and possible role in enkephalinergic transmission. Int J Neurol. 1980;14:195-204.

37. Letarte M, Vera S, Tran R, Addis JB, Onizuka RJ, Quackenbush EJ, et al. Common acute lymphocytic leukemia antigen is identical to neutral endopeptidase. J Exp Med. 1988;168:1247-53.

38. Grimm MO, Mett J, Stahlmann CP, Haupenthal VJ, Zimmer VC, Hartmann T. Neprilysin and AB clearance: impact of the APP intracellular domain in NEP regulation and implications in Alzheimer's disease. Front Aging Neurosci. 2013;5:98.

39. Iwata N, Tsubuki S, Takaki Y, Shirotani K, Lu B, Gerard NP, et al. Metabolic regulation of brain A $\beta$ by neprilysin. Science. 2001;292:1550-2.

40. Barnes K, Matsas R, Hooper N, Turner A, Kenny A. Endopeptidase-24.11 is striosomally ordered in pig brain and, in contrast to aminopeptidase $\mathrm{N}$ and peptidyl dipeptidase A ('angiotensin converting enzyme'), is a marker for a set of striatal efferent fibres. Neuroscience. 1988;27:799-817.

41. Nalivaeva N, Belyaev N, Zhuravin I, Turner A. The Alzheimer's amyloiddegrading peptidase, neprilysin: can we control it? Int J Alzheimers Dis. 2012;2012:383796

42. Li C, Hersh LB. Characterization of the promoter region of the rat neprilysin gene. Arch Biochem Biophys. 1998;358:189-95.

43. Barnes K, Doherty S, Turner AJ. Endopeptidase-24.11 is the integral membrane peptidase initiating degradation of somatostatin in the hippocampus. J Neurochem. 1995;64:1826-32.

44. Saito T, Iwata N, Tsubuki S, Takaki Y, Takano J, Huang S, et al. Somatostatin regulates brain amyloid $\beta$ peptide $A \beta 42$ through modulation of proteolytic degradation. Nat Med. 2005;11:434-9.

45. Pardossi-Piquard R, Petit A, Kawarai T, Sunyach C, da Costa CA, Vincent B, et al. Presenilin-dependent transcriptional control of the $A \beta$-degrading enzyme neprilysin by intracellular domains of $\beta A P P$ and APLP. Neuron. 2005;46:541-54.

46. Li C, Booze RM, Hersh LB. Tissue-specific expression of rat neutral endopeptidase (neprilysin) mRNAs. J Biol Chem. 1995;270:5723-8. 
47. Cattaneo F, Parisi M, Ammendola R. Distinct signaling cascades elicited by different formyl peptide receptor 2 (FPR2) agonists. Int J Mol Sci. 2013;14:7193-230.

48. Enrich C, Rentero C, de Muga SV, Reverter M, Mulay V, Wood P, et al. Annexin A6-linking Ca 2 signaling with cholesterol transport. Biochim Biophys Acta, Mol Cell Res. 2011;1813:935-47.

49. Yona S, Heinsbroek SE, Peiser L, Gordon S, Perretti M, Flower RJ. Impaired phagocytic mechanism in annexin 1 null macrophages. Br J Pharmacol. 2006;148:469-77.

50. Yazawa H, Yu ZX, Le Takeda Y, Gong W, Ferrans VJ, et al. Beta amyloid peptide (AB42) is internalized via the G-protein-coupled receptor FPRL1 and forms fibrillar aggregates in macrophages. FASEB J. 2001;15:2454-62.

51. Brandenburg L, Konrad M, Wruck C, Koch T, Pufe T, Lucius R. Involvement of formyl-peptide-receptor-like-1 and phospholipase $D$ in the internalization and signal transduction of amyloid beta 1-42 in glial cells. Neuroscience. 2008;156:266-76

52. Iribarren P, Zhou Y, Hu J, Le Y, Wang JM. Role of formyl peptide receptor-like 1 (FPRL1/FPR2) in mononuclear phagocyte responses in Alzheimer disease. Immunol Res. 2005;31:165-76.

53. Brandenburg L, Konrad M, Wruck CJ, Koch T, Lucius R, Pufe T. Functional and physical interactions between formyl-peptide-receptors and scavenger receptor MARCO and their involvement in amyloid beta 1-42-induced signal transduction in glial cells. J Neurochem. 2010;113:749-60.

54. Patel DM, Ahmad SF, Weiss DG, Gerke V, Kuznetsov SA. Annexin A1 is a new functional linker between actin filaments and phagosomes during phagocytosis. J Cell Sci. 2011;124:578-88.

55. Hayes MJ, Rescher U, Gerke V, Moss SE. Annexin-actin interactions. Traffic. 2004:5:571-6.

56. Yang YH, Aeberli D, Dacumos A, Xue JR, Morand EF. Annexin-1 regulates macrophage IL-6 and TNF via glucocorticoid-induced leucine zipper. J Immunol. 2009;183:1435-45.

\section{Submit your next manuscript to BioMed Central and we will help you at every step:}

- We accept pre-submission inquiries

- Our selector tool helps you to find the most relevant journal

- We provide round the clock customer support

- Convenient online submission

- Thorough peer review

- Inclusion in PubMed and all major indexing services

- Maximum visibility for your research

Submit your manuscript at www.biomedcentral.com/submit 